Vietnam Journal of Mechanics, NCST of Vietnam Vol. 25, 2003, No 4 (243 - 254)

\title{
LARGE DEFLECTION ANALYSIS OF FRAMES BY ELEMENTS CONTAINING HIGHER-ORDER TERMS
}

\author{
NGUYEN Dinh KIEN ${ }^{1}$ \\ Institute of Mechanics, NCST of Vietnam \\ Do QUOC QUANG \\ Research Institute of Technology for Machinery, Ministry of Industry
}

\begin{abstract}
In this paper, the beam elements using higher-order terms for large deflection analysis of elastic frames are discussed. The elements based on the co-rotational method are derived using the strain energy and effective strains. The arc-length method is employed as numerical algorithm to compute the equilibrium paths. A number of numerical examples are studied to verify and compare the developed formulations. The obtained results show that while the inclusion of second-order local rotation contributes to some improvement in the accuracy, the higher-order axial strain hardly improves the numerical results. With the employment of the higher-order term elements, the accuracy in numerical analysis may be attained at coarser meshes.
\end{abstract}

\section{Introduction}

The co-rotational method is an efficient tool in development of nonlinear elements for structural analysis. The method, which employed an element attached coordinate system, results in simple expressions for the local tangent stiffness matrix and internal force vector. By eliminating the rigid rotation and translation from the formulations in the local system, the co-rotational method may allow employing simple definition of local strain, and the element based on linear definition of local strain has been developed [1]. The inclusion of higher-order terms may lead to more accurate elements, but faces some difficulties such as a large amount of calculation may be required. However, recent work shows that the symbolic computational softwares such as Mathematica or Maple can be used as very efficient tools in developing complex elements for nonlinear analysis [2]. Highlighted by the research, the present work develops higher-order beam elements based on Bernoulli's assumptions for large deflection analysis of elastic frames by using the co-rotational method and with the aid of Maple. A computer code based on the constructing formulations and the arc-length method is developed and employed to analyze various frames. The numerical results are used to verify the elements and compare to the one previously developed using linear definition for the local strain.

\footnotetext{
${ }^{1}$ On the leave for the College of Engineering, Nihon University, Japan
} 


\section{Strain employment}

In the context of finite element method, the most suitable strain for large deflection problems is the Green's measure [3], and for a $2 D$ beam element based on Bernoulli's assumptions in the $(x, z)$ system, the Green's strain is written by

$$
\varepsilon_{x}=\varepsilon_{x 0}+z \kappa=\frac{d u}{d x}+\frac{1}{2}\left(\frac{d u}{d x}\right)^{2}+\frac{1}{2}\left(\frac{d w}{d x}\right)^{2}-z \frac{d^{2} w}{d x^{2}}
$$

where $u, w$ are axial and lateral displacements, respectively; $\varepsilon_{x 0}$ is the strain of the fiber on the neutral axis; $\kappa=-d^{2} w / d x^{2}$ is the curvature. By omitting some higher-order terms in the expression for $\varepsilon_{x 0}$ in (2.1), the two simplified theories are obtained

$$
\text { engineering : } \varepsilon_{x 0}=\frac{d u}{d x} ; \quad \text { shallow } \operatorname{arch}: \varepsilon_{x 0}=\frac{d u}{d x}+\frac{1}{2}\left(\frac{d w}{d x}\right)^{2} \text {. }
$$

Using the co-rotational method, the simplified theories can be employed for local strain definition to develop finite elements, but more accurate element is expected by using the Green's strain or the shallow arch theory. However, when interpolating the displacement field inside the element from the nodal degrees of freedom (d.o.f), we cannot use lower-order functions for $w$ than the cubic such as the Hermitian formulas, while linear functions are often adopted for $u$. This unbalance interpolation scheme leads to the locking element which is not able to analyze the bending problems $[4,5]$. Strictly speaking, as seen in (2.1), we can adopt quintic functions for $u$ so that a balance with cubic functions for $w$ is achieved, but such an interpolation scheme would be extremely cumbersome. A number of techniques can be applied to remove the locking problem $[6,7]$, and in this study an effective strain used in [7] to ensure a constant membrane strain is employed herewith

$$
\varepsilon_{e f}=\frac{1}{L} \int_{0}^{L} \varepsilon_{x 0} d x=\frac{1}{L} \int_{0}^{L}\left[\frac{d u}{d x}+\frac{1}{2}\left(\frac{d u}{d x}\right)^{2}+\frac{1}{2}\left(\frac{d w}{d x}\right)^{2}\right] d x
$$

with $L$ is the element length. The effective strain (2.2) is used in place of the strain $\varepsilon_{x 0}$ in (2.1) to develop the finite element formulations in the below. The formulations corresponding to shallow arch theory are directly obtained by omitting the term concerning $\left(\frac{d u}{d x}\right)^{2}$ in $(2.2)$.

\section{Co-rotational method and beam kinematics}

The co-rotational method for developing nonlinear elements has been discussed in $[7,8]$ in various ways, but for completeness the main points of the method for constructing beam elements discussed in $[1]$ are summarized herewith. 


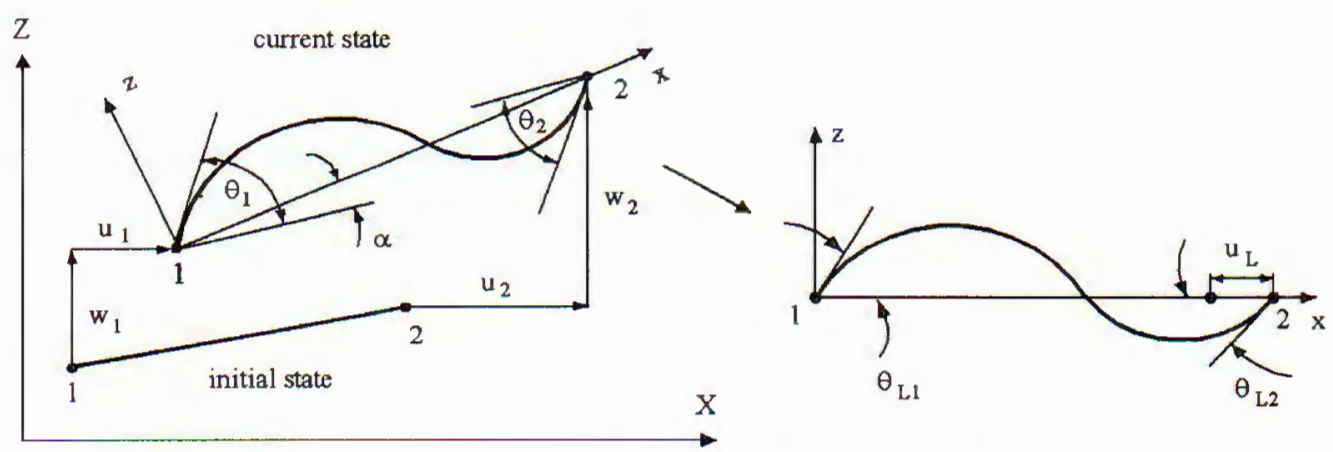

Fig. 1. Beam kinematics in global and local coordinate systems

Two coordinate systems, as shown in the Fig. 1, are employed in the method, the fixed global $(X, Z)$ and the moving local $(x, z)$. The local system is chosen as well as its original is placed at node 1 , and the axis $x$ is directed from node 1 to node 2. The vector of nodal d.o.f in the global and local systems respectively are

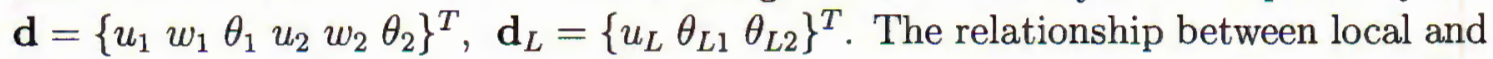
global d.o.f is given by

$$
u_{L}=L_{n}-L ; \quad \theta_{L 1}=\theta_{1}-\alpha ; \quad \theta_{L 2}=\theta_{2}-\alpha,
$$

where $L$ and $L_{n}$ are the initial and current lengths of the element

$$
\begin{aligned}
L & =\sqrt{\left(x_{2}-x_{1}\right)^{2}+\left(z_{2}-z_{1}\right)^{2}} \\
L_{n} & =\sqrt{\left(x_{2}-x_{1}+u_{2}-u_{1}\right)^{2}+\left(z_{2}-z_{1}+w_{2}-w_{1}\right)^{2}}
\end{aligned}
$$

with $\left(x_{1}, z_{1}\right)$ and $\left(x_{2}, z_{2}\right)$ are the initial coordinates of nodes 1 and $2 ; \alpha$ is the rigid rotation, expressed through the global d.o.f by

$$
\alpha=\operatorname{arctg}\left[\frac{\left(x_{2}-x_{1}\right)\left(w_{2}-w_{1}\right)-\left(z_{2}-z_{1}\right)\left(u_{2}-u_{1}\right)}{\left(x_{2}-x_{1}\right)\left(x_{2}-x_{1}+u_{2}-u_{1}\right)+\left(z_{2}-z_{1}\right)\left(z_{2}-z_{1}+w_{2}-w_{1}\right)}\right] .
$$

Using the co-rotational method, the internal force vector and tangent stiffness method of the element are firstly constructed in the local system and then transferred to the global one. The internal force vector is derived by differentiating the strain energy $U$ (the same in the two systems) with respect to the global nodal d.o.f as $[7]$

$$
\mathbf{f}_{i}=\frac{\partial U}{\partial \mathbf{d}}=\frac{\partial U}{\partial \mathbf{d}_{L}} \frac{\partial \mathbf{d}_{L}}{\partial \mathbf{d}}=\mathbf{A}_{1}^{T} \mathbf{f}_{L i}
$$

where $\mathbf{f}_{i}=\left\{\begin{array}{llllll}N_{1} & Q_{1} & M_{1} & N_{2} & Q_{2} & M_{2}\end{array}\right\}^{T}$ and $\mathbf{f}_{L i}=\left\{\begin{array}{lll}N_{L} & M_{L 1} & M_{L 2}\end{array}\right\}^{T}$ are the global and local internal force vectors, respectively; $\mathbf{A}_{1}$ is the matrix transformation, computed 
from (3.1) as

$$
\underset{3 \times 6}{\mathbf{A}_{1}}=\left[A_{1 i j}\right]=\left[\frac{\partial d_{L i}}{\partial d_{j}}\right] .
$$

Having the internal force vector computed, the tangent stiffness matrix is obtained by differentiating the internal force vector (3.4) with respect to the global nodal d.o.f as

$$
\begin{aligned}
\underset{6 \times 6}{\mathbf{k}_{t}} & =\frac{\partial \mathbf{f}_{i}}{\partial \mathbf{d}}=\mathbf{A}_{1}^{T} \frac{\partial \mathbf{f}_{L i}}{\partial \mathbf{d}_{L}} \mathbf{A}_{1}+N_{L} \frac{\partial^{2} u_{L}}{\partial \mathbf{d}^{2}}+M_{L 1} \frac{\partial^{2} \theta_{L 1}}{\partial \mathbf{d}^{2}}+M_{L 2} \frac{\partial^{2} \theta_{L 2}}{\partial \mathbf{d}^{2}} \\
& =\mathbf{A}_{1}^{T} \mathbf{k}_{L t} \mathbf{A}_{1}+N_{L} \mathbf{A}_{2}+M_{L 1} \mathbf{A}_{3}+M_{L 2} \mathbf{A}_{4},
\end{aligned}
$$

where $\mathbf{k}_{2 \times 3}$ is the local tangent stiffness matrix; $\mathbf{A}_{2}, \mathbf{A}_{3}, \mathbf{A}_{4}$ are the transformation matrices, again computed from (3.1) as

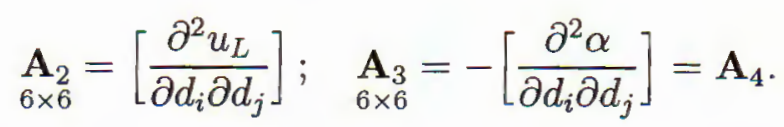

Using the equations (3.4)-(3.7), the remain work for obtaining the finite element formulations is to construct the internal force vector and tangent stiffness matrix in the local system.

\section{Local formulations}

As mentioned in the previous section, the internal force vector can be computed from the strain energy, and for our bending problem of Bernoulli beam, the strain energy is given by

$$
U=\frac{1}{2} \int_{0}^{L}\left(E A \varepsilon_{x 0}^{2}+E I \kappa^{2}\right) d x
$$

where $E A, E I$ are axial and bending rigidities. To express the strain energy $U$ in terms of the local nodal d.o.f we need to interpolate the displacement fields, and the linear function for $u$ and Hermitian ones for $w$ are again employed herewith. Keeping in mind that $u_{L 1}=w_{L 1}=w_{L 2}=0$ and $u_{L 2}$ is now denoted by $u_{L}$, the displacement fields $u$ and $w$ are interpolated through the local d.o.f by

$$
u=\frac{x}{L} u_{L} ; \quad w=\left(x-\frac{2 x^{2}}{L}+\frac{x^{3}}{L^{2}}\right) \theta_{L 1}+\left(-\frac{x^{2}}{L}+\frac{x^{3}}{L^{2}}\right) \theta_{L 2} .
$$

Substituting (4.1) into in (2.2), the effective strain is written by

$$
\varepsilon_{e f}=\frac{u_{L}}{L}+\frac{u_{L}^{2}}{2 L^{2}}+\frac{1}{15}\left(\theta_{L 1}^{2}-\frac{1}{2} \theta_{L 1} \theta_{L 2}+\theta_{L 2}^{2}\right)
$$


From (4.2) and (4.3), with the note that $\varepsilon_{e f}$ is now used in place of $\varepsilon_{x 0}$, the strain energy (4.1) is given by

$$
U=\frac{L}{2} E A\left(\frac{u_{L}}{L}+\frac{u_{L}^{2}}{2 L^{2}}+\frac{\theta_{L 1}^{2}}{15}-\frac{\theta_{L 1} \theta_{L 2}}{30}+\frac{\theta_{L 2}^{2}}{15}\right)^{2}+\frac{2}{L} E I\left(\theta_{L 1}^{2}+\theta_{L 1} \theta_{L 2}+\theta_{L 2}^{2}\right) .
$$

The local internal forces are now obtained by differentiating the strain energy (4.4) with respect to the local d.o.f

$$
\begin{aligned}
N_{L} & =E A\left(1+\frac{u_{L}}{L}\right)\left(\frac{u_{L}}{L}+\frac{u_{L}^{2}}{2 L^{2}}+\frac{\theta_{L 1}^{2}}{15}-\frac{\theta_{L 1} \theta_{L 2}}{30}+\frac{\theta_{L 2}^{2}}{15}\right), \\
M_{L 1} & =\frac{L}{30} E A\left(4 \theta_{L 1}-\theta_{L 2}\right)\left(\frac{u_{L}}{L}+\frac{u_{L}^{2}}{2 L^{2}}+\frac{\theta_{L 1}^{2}}{15}-\frac{\theta_{L 1} \theta_{L 2}}{30}+\frac{\theta_{L 2}^{2}}{15}\right)+\frac{2}{L} E I\left(2 \theta_{L 1}+\theta_{L 2}\right), \\
M_{L 2} & =\frac{L}{30} E A\left(-\theta_{L 1}+4 \theta_{L 2}\right)\left(\frac{u_{L}}{L}+\frac{u_{L}^{2}}{2 L^{2}}+\frac{\theta_{L 1}^{2}}{15}-\frac{\theta_{L 1} \theta_{L 2}}{30}+\frac{\theta_{L 2}^{2}}{15}\right)+\frac{2}{L} E I\left(2 \theta_{L 1}+\theta_{L 2}\right) .
\end{aligned}
$$

The coefficients of the local tangent stiffness matrix are computed by differentiating the local internal forces (4.5) or twice differentiating the strain energy (4.4) with respect to the local d.o.f

$$
\begin{aligned}
k_{L t}(1,1)= & \frac{1}{L} E A\left[\left(1+\frac{u_{L}}{L}\right)^{2}+\left(\frac{u_{L}}{L}+\frac{u_{L}^{2}}{2 L^{2}}+\frac{\theta_{L 1}^{2}}{15}-\frac{\theta_{L 1} \theta_{L 2}}{30}+\frac{\theta_{L 2}^{2}}{15}\right)\right] \\
k_{L t}(1,2)= & \frac{1}{30} E A\left(1+\frac{u_{L}}{L}\right)\left(4 \theta_{L 1}-\theta_{L 2}\right) \\
k_{L t}(1,3)= & \frac{1}{30} E A\left(1+\frac{u_{L}}{L}\right)\left(-\theta_{L 1}+4 \theta_{L 2}\right) \\
k_{L t}(2,2)= & \frac{L}{30} E A\left[\frac{1}{30}\left(4 \theta_{L 1}-\theta_{L 2}\right)^{2}+4\left(\frac{u_{L}}{L}+\frac{u_{L}^{2}}{2 L^{2}}+\frac{\theta_{L 1}^{2}}{15}-\frac{\theta_{L 1} \theta_{L 2}}{30}+\frac{\theta_{L 2}^{2}}{15}\right)\right] \\
& \quad+\frac{4}{L} E I \\
k_{L t}(3,3)= & \frac{L}{30} E A\left[\frac{1}{30}\left(-\theta_{L 1}+4 \theta_{L 2}\right)^{2}+4\left(\frac{u_{L}}{L}+\frac{u_{L}^{2}}{2 L^{2}}+\frac{\theta_{L 1}^{2}}{15}-\frac{\theta_{L 1} \theta_{L 2}}{30}+\frac{\theta_{L 2}^{2}}{15}\right)\right] \\
& \quad+\frac{4}{L} E I \\
k_{L t}(2,3)= & \frac{L}{30} E A\left[\frac{\left(4 \theta_{L 1}-\theta_{L 2}\right)\left(4 \theta_{L 2}-\theta_{L 1}\right)}{30}-\left(\frac{u_{L}}{L}+\frac{u_{L}^{2}}{2 L^{2}}+\frac{\theta_{L 1}^{2}}{15}-\frac{\theta_{L 1} \theta_{L 2}}{30}+\frac{\theta_{L 2}^{2}}{15}\right)\right] \\
& \quad+\frac{2}{L} E I \\
k_{L t}(2,1)= & k_{L t}(1,2) ; \quad k_{L t}(3,1)=k_{L t}(1,3) ; \quad k_{L t}(3,2)=k_{L t}(2,3) .
\end{aligned}
$$

The expressions/for the local internal forces and tangent stiffness matrix seem complex, but they are easily obtained with the aid of symbolic software Maple [9], and the Maple code for deriving the equations (4.3)-(4.6) is given in the Appendix. 
The formulations for the element using shallow arch theory are directly obtained by omitting the terms containing $u_{L}^{2}$ in the equation (4.3), that is in the expression for the effective strain in the Appendix. Combining with (3.4)-(3.7), the equations (4.5) and (4.6) are enough for computing internal force vector and tangent stiffness matrix at the global system.

\section{Numerical algorithm}

The obtained formulations at the element level are assembled into structural internal force vector $\mathbf{F}_{\text {in }}$ and tangent stiffness matrix $\mathbf{K}_{t}$ to construct the equilibrium equations, which can be written in the form

$$
\mathbf{R}(\mathbf{D}, \lambda)=\mathbf{F}_{\text {in }}-\mathbf{F}_{\text {ex }}=\mathbf{F}_{\text {in }}-\lambda \mathbf{f}_{\mathrm{ex}}=\mathbf{0},
$$

where $\mathbf{R}$ is the out of balance force vector between the vectors of internal forces $\mathbf{F}_{\text {in }}$ and external forces $\mathbf{F}_{\text {ex }} ; \mathbf{D}$ - the vector of structural nodal d.o.f; $\lambda$ is the loading parameter, and $\mathbf{f}_{\mathrm{ex}}$ - the fixed normalized external force vector. The equation (5:1) can be solved by the incremental iterative technique based on Newton-Raphson method, in which an iterative displacements are computed as $\delta \mathbf{D}=-\mathbf{K}_{t}^{-1} \mathbf{R}$. To trace complete equilibrium paths, the arc-length method $[7,8]$ is employed, and (5.1) is supplemented by a constraint equation

$$
\Delta \mathbf{D}^{T} \Delta \mathbf{D}+\psi^{2} \Delta \lambda^{2} \mathbf{f}_{\mathrm{ex}}^{T} \mathbf{f}_{\mathrm{ex}}=\Delta L^{2},
$$

where $\Delta \mathbf{D}$ is the incremental displacements, accumulated from the iterative displacements $\delta \mathbf{D} ; \Delta L$ is the known value; $\psi$ is the parameter. Figure 2 shows how to compute a new point $\left(D, \lambda f_{\text {ex }}\right)$ from the current equilibrium point $\left(D_{0}, \lambda_{0} f_{e x}\right)$ by using the constraint equation (5.2). For the sake of simplicity, the figure is illustrated for the two-dimensional case of load-displacement space.
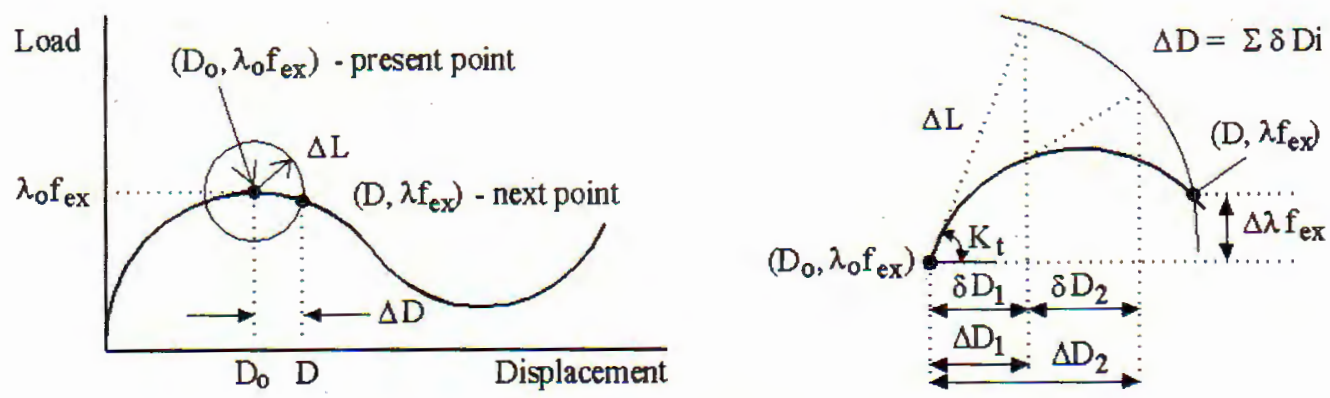

Fig. 2. Solution method for tracing equilibrium paths

The total displacements $\mathbf{D}$ are updated from the increment displacements $\Delta \mathbf{D}$ for every iteration, and the out of balance force vector $\mathbf{R}(\mathbf{D}, \lambda)$ is then recomputed by equation (5.1). This iterative process is terminated when a convergence criterion 
is satisfied, and in the present study the criterion based on load-control technique is employed as

$$
\|\mathbf{R}\|<\beta\left\|\mathbf{F}_{\mathrm{ex}}\right\|
$$

where $\beta$ is a small constant, called tolerance. The value of $\Delta L$ in (5.2) is first given as input data, and then automatically is computed for the next increment by the automatic increment method adopted from $[10]$. A value for the maximum iteration number is set out as input data, and if the convergence is not achieved within this value, the iterative process is stopped, and $\Delta L$ is reduced by haft.

\section{Numerical examples}

The obtained formulations and discussed algorithm are implemented into a compute code using MATLAB [11]. Two developed elements, the Green element (GE) using strain defined by (2.2), and the other using the shallow arch theory (SE), have been used to analyze problems in Figure 3. It is noted that the units of measurement of some problems in the figure have been converted to the SI system from their

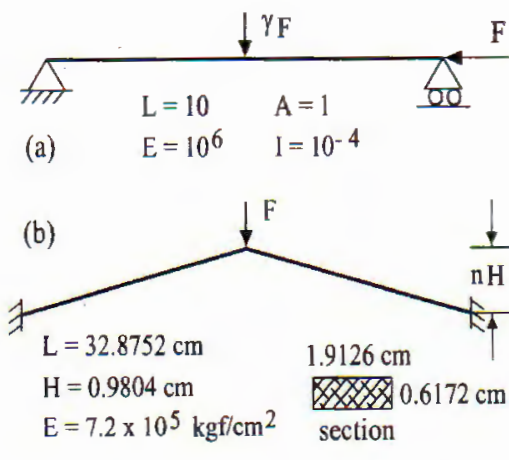

(d)

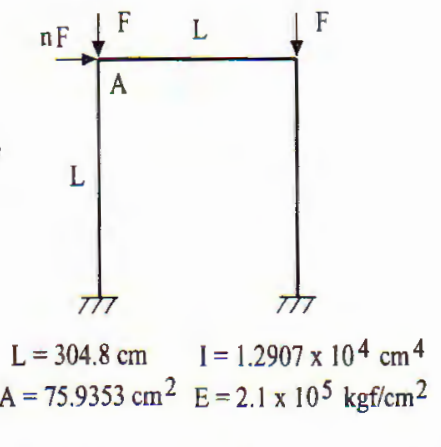

(c)

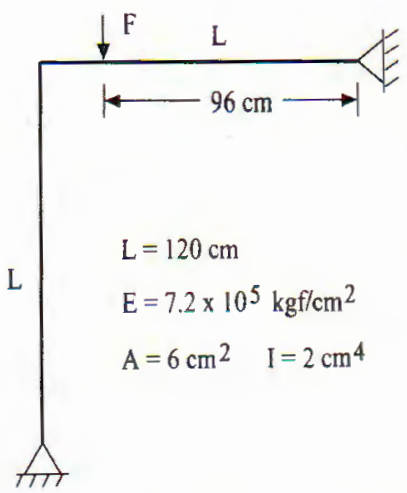

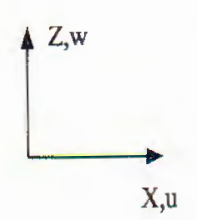

(e)

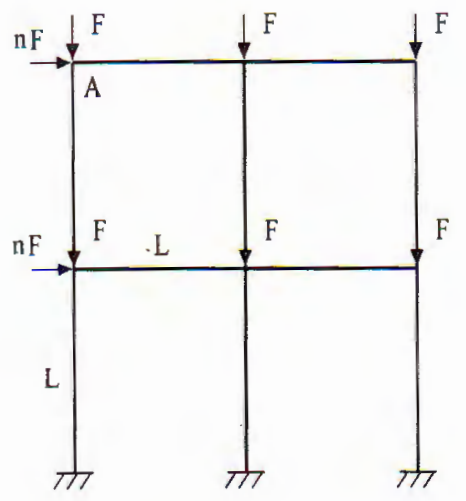

Fig. 3. Test problems for verifying the elements 
original sources. The engineering element (EE) developed in [1], is also employed for the purpose of comparison. The first two problems are chosen to verify and compare the elements since their analytical solutions are available. The remain problems are employed to test the ability of the elements as well as the developed computer code in handling the complex behavior of the structures and in working with more practical structures. The geometry and material data for each problem are given in the figure. A tolerance $\beta=10^{-4}$ is used in all the analyses.

The elastica. The elastica of the Euler beam with analytical solution given in [12] is one of the classical examples to test the nonlinear elements. This example analyzes the behaviour of the Euler beam in Figure 3a, where $\gamma F$ is a small perturbation. Figure $4 \mathrm{a}$ shows the computed load-deflection curves at the middle point of the beam using 4 and $8 \mathrm{EEs}$ and GEs, where $F_{c r}$ denoted the critical load. To compare the elements, an enlargement of the post-buckling part of the curves is shown in the Figure $4 \mathrm{~b}$. The SE was also used in the analysis but its results are not shown in the figures due to they are too close to those obtained by GE. The EE element which is constructed by omitting the higher-order terms exhibits some softer in the large deflection behavior of the beam, and this tendency is more clear in the coarse mesh (4 elements). Using 8 elements, both EE and GE are good in describing postbuckling behavior of the beam, but with the note that the line $(-w / L=0.4)$ is the tangent of the analytical solution [12], the GE is much more accurate in comparison with EE. The analysis was also carried out with various values of $\gamma$, but no much difference on the sensitivity to the perturbation of the elements has been observed.
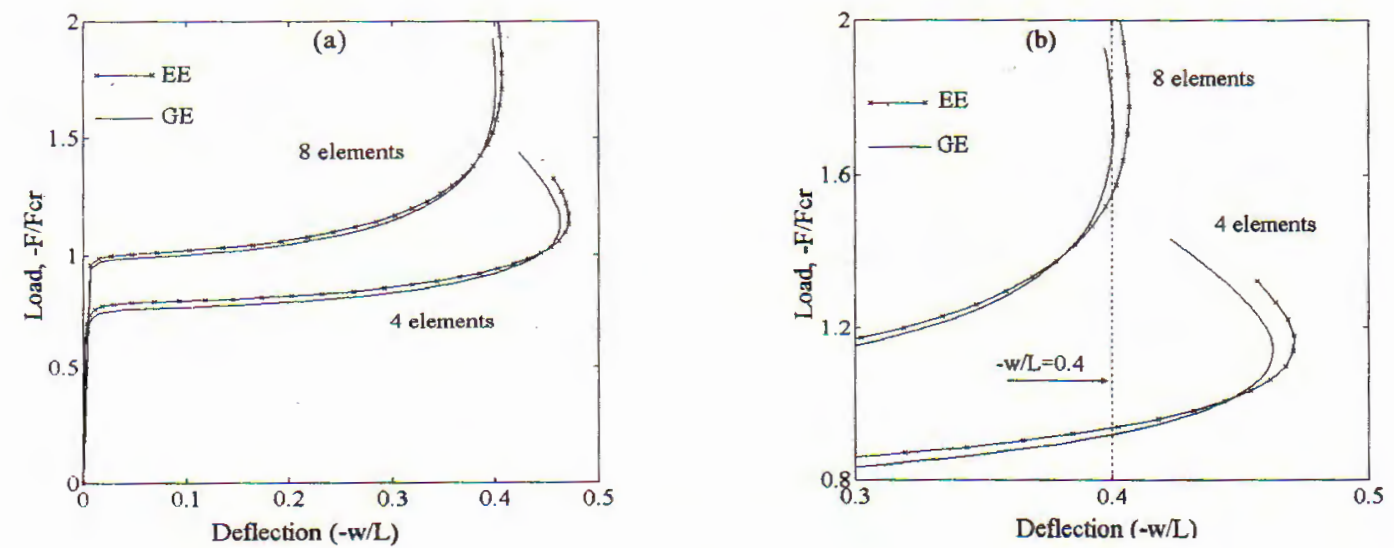

Fig. 4. Load-deflection curves of Euler beam analyzed by different type and number of elements; $\gamma=0.002$

Toggle frame. For the case $n=1$, the toggle frame shown in Figure $3 \mathrm{~b}$ has been analytically studied by Williams [13] and numerically by various authors $[14,15]$. The computed load-deflection curves of the frame are shown in Figure 5a for the case $n=1$, and in Figure $5 \mathrm{~b}$ for the case $n=0.5$ and $n=1.2$. Five elements for each beam have been used in the analyses. The GE is exhibited more accurate, and 
the EE is again softer comparing to its counterpart. The curves computed by SE are not shown in the figure either, since they are also too close to the ones obtained by GE.
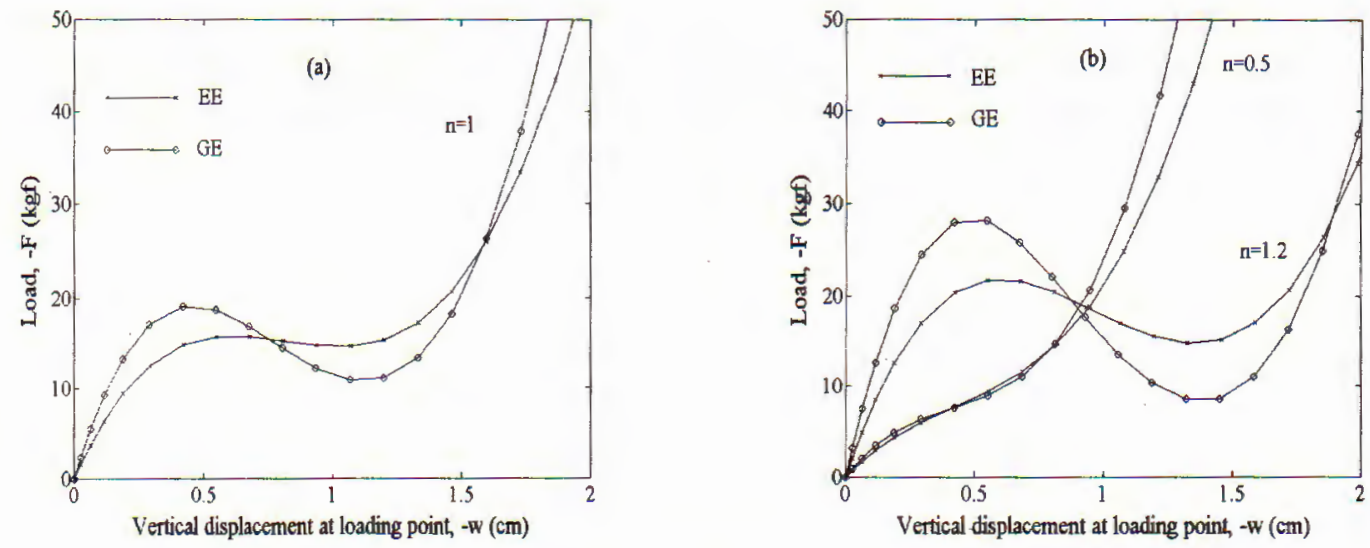

Fig. 5. Load-deflection curves of toggle frame analyzed by various elements

Asymmetric frame. The asymmetric frame in Figure $3 c$ was numerically analyzed in $[15,16]$, and it shows snap-through and snap-back characteristics. This example is employed to verify the ability of the computer code in handling those complex characteristics of the structure. The load-deflection curves of the frame computed by ûsing five GEs for each beam are given in Figure 6a. Very good agrement with the result in [16] was obtained. It is necessary to note that some difficulties in convergence were observed at the regions around points $\mathrm{A}$ and $\mathrm{B}$ in Figure $6 \mathrm{a}$, and $\Delta L$ in these regions has been reduced to about one fifth of its input value. The deformed configurations of the discrete frame at various load levels (not computed in the previous works) are shown in Figure 6b.
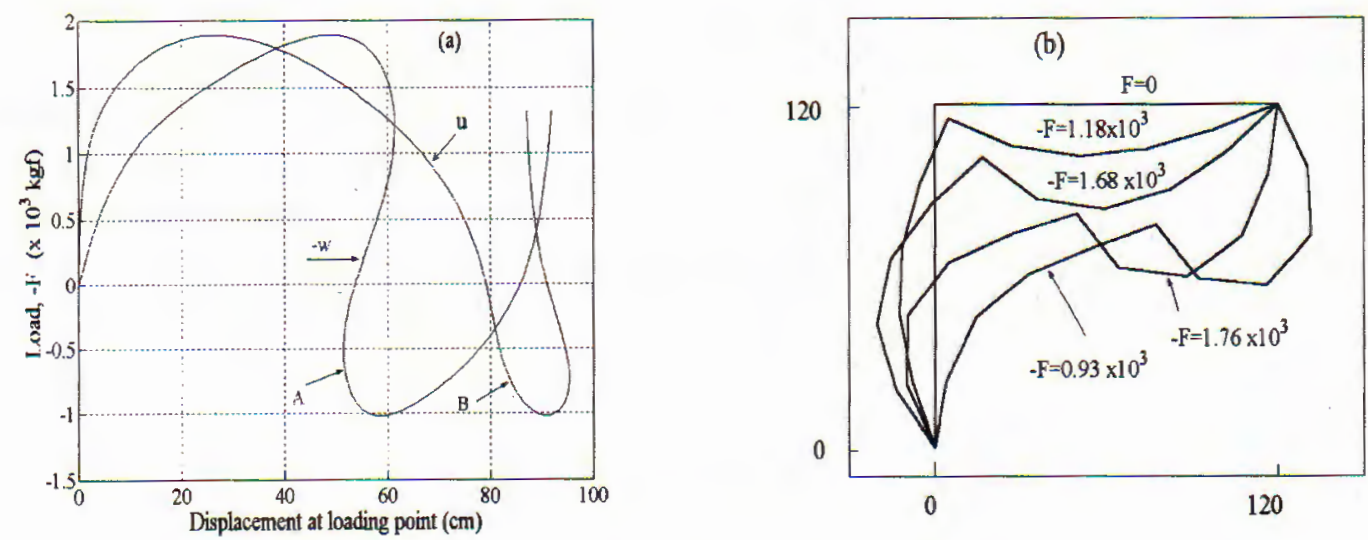

Fig. 6. Load-deflection curves of asymmetric frame (a), and deformed configurations of discrete frame (b) 
Portal and two-bay two-storey frames. The portable frame shown in Figure $3 \mathrm{~d}$ having geometry and material data taken from [15], and the two-bay two-storey frame shown in Figure 3e as an extension of the portable frame are used to verify the computer code in working with more practical structures. Figures $7 \mathrm{a}$ and $7 \mathrm{~b}$ respectively show the load-displacement curves of the structures with various values of $n$. A good agrement with the results in [15] was seen, at leats with the horizontal displacement up to $200 \mathrm{~cm}$. The values of the horizontal displacement beyond 200 $\mathrm{cm}$ is not reported in [15].
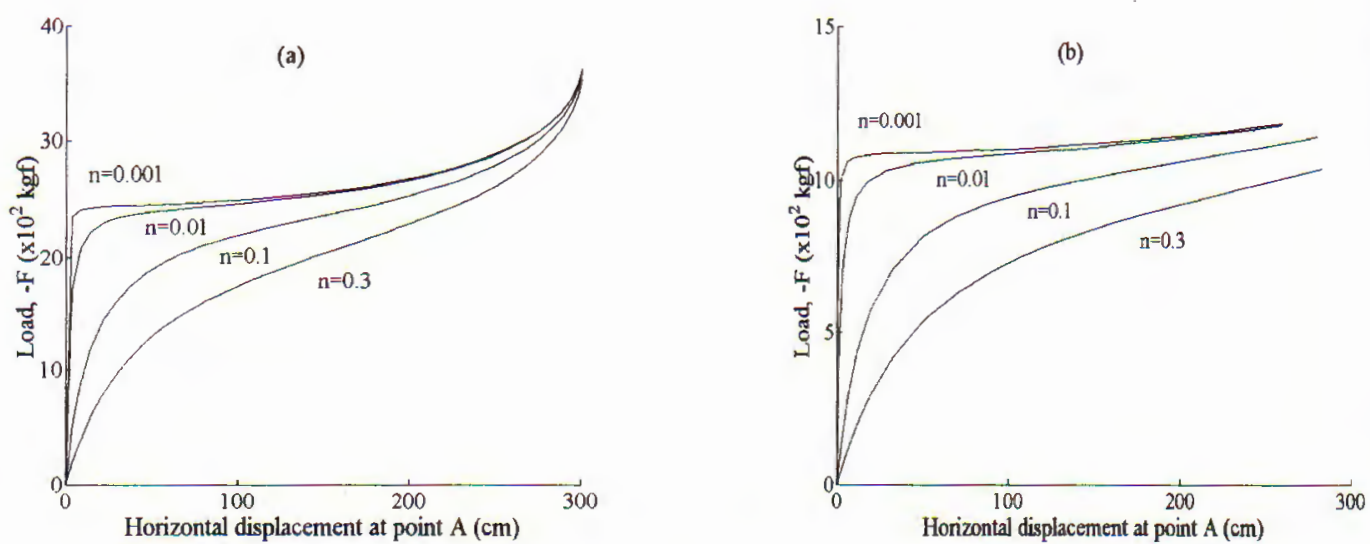

Fig. 7. Load-displacement curves of portable frame (a), and two-bay two-storey frame (b)

\section{Conclusions}

The present work described the finite element formulations and numerical algorithm for geometrically nonlinear analysis of elastic frames. The elements employing higher-order terms show better accurate comparing with the one using the engineering strain. The developed formulations have complex forms, but could be derived and handled without difficulties by using the symbolic software Maple.

Five examples have been employed to verify and demonstrate the accuracy and efficiency of the developed elements and computer code. The two developed elements, GE and SE show almost no difference in the numerical results. The difference between the high-order term elements and the engineering element was observed at the large displacement regions, and the tendency is more clear in the coarse mesh.

\section{Appendix}

\# Maple code for internal forces and tangent stiffness matrix restart; with(linalg);

$\mathrm{Nu}:=\mathrm{x} / \mathrm{L} ; \mathrm{Nw} 1:=\mathrm{x}-2^{*} \mathrm{x}^{\wedge} 2 / \mathrm{L}+\mathrm{x}^{\wedge} 3 / \mathrm{L} / \mathrm{L} ; \mathrm{Nw} 2:=-\mathrm{x}^{\wedge} 2 / \mathrm{L}+\mathrm{x}^{\wedge} 3 / \mathrm{L} / \mathrm{L}$;

Nux: $=\operatorname{diff}(\mathrm{Nu}, \mathrm{x}) ; \mathrm{Nw} 1 \mathrm{x}:=\operatorname{diff}(\mathrm{Nw} 1, \mathrm{x}) ; \mathrm{Nw} 2 \mathrm{x}:=\operatorname{diff}(\mathrm{Nw} 2, \mathrm{x})$

$N w 1 x x:=\operatorname{diff}(N w 1 x, x) ; N w 2 x x:=\operatorname{diff}(N w 2 x, x)$ 
\# effective strain and curvature, omit " $1 / 2^{*}\left(\mathrm{Nux}{ }^{*} \mathrm{uL}\right)^{\wedge} 2$ " term for SE element

Eef: $=1 / L^{*} \operatorname{int}\left(\mathrm{Nux}^{*} \mathrm{uL}+1 / 2^{*}\left(\mathrm{Nux} \mathrm{uL}^{*}\right)^{\wedge} 2+\left(\mathrm{Nw} 1 \mathrm{x}^{*} \text { thetaL } 1+\mathrm{Nw} 2 \mathrm{x}^{*} \text { thetaL2 }\right)^{\wedge} 2, \mathrm{x}=0\right.$...L $)$;

Eef:=simplify $($ Eef $)$;

kappa:=-(Nw1xx*thetaL1+Nw2xx*thetaL2);

\# the strain energy

$\mathrm{U} 1:=1 / 2 * \operatorname{int}\left(\mathrm{EA}^{*} \operatorname{Eef}^{\wedge} 2, \mathrm{x}=0 . . \mathrm{L}\right) ; \mathrm{U} 2:=1 / 2 * \operatorname{int}\left(\mathrm{EI}^{*} k_{\mathrm{kappa}}{ }^{\wedge} 2, \mathrm{x}=0 \ldots \mathrm{L}\right) ; \mathrm{U}:=\mathrm{U} 1+\mathrm{U} 2$;

\# the internal forces and stiffness matrix

$\mathrm{fLi}:=\operatorname{grad}(\mathrm{U},[\mathrm{uL}$, thetaL 1, thetaL2 $])$;

$\mathrm{KLt}:=\operatorname{hessian}(\mathrm{U},[\mathrm{uL}$, thetaL1, thetaL2]);

\section{REFERENCES}

1. Nguyen D. K. A non-linear element for analyzing elastic frame at large deflections. Vietnam Journal of Mechanics 22 (2000), 19-28.

2. Eriksson A. and Pacoste C. Symbolic software tools in the development of finite elements. Computer \& Structure 72 (1999), 579-593.

3. Bathe K. J. Finite element procedures. Prentice Hall, Englewood Cliff, N. J., 1996.

4. Fung Y. C. and Tong P. Classical and computational solid mechanics. World Scientific. Singapore, 2001.

5. Crisfield M. A. Finite elements and solution procedures for structural analysis. Volume 1: Linear analysis. Pineridge Press, Swansea, 1986.

6. Luo Y. H. Explanation and elimination of shear locking and membrane locking with field consistence approach. Computer Methods in Applied Mechanics and Engineering 162 (1998), 249-269.

7. Crisfield M. A. Non-linear finite element analysis of solids and structures, Volume 1: Essentials. John Wiley \& Sons, Chichester, 1991.

8. Belytschko T, Liu W. K. and Moran B. Nonlinear finite elements for continua and structures. John Wiley \& Sons, Chichester, 2000.

9. Maple V, Language reference manual, Spring-Verlag, New York, 1991.

10. Crisfield M. A. A fast incremental/iterative solution procedure that handles "snap-through". Computers \& Structures, 13 (1981), 55-62.

11. Matlab, High-performance numeric computation and visualization sofware. Reference guide, The Math Works Inc., New York, 1992.

12. Shames I. H. and Dym C. L. Energy and finite element methods in structural mechanics. McGraw-Hill, New York, 1985.

13. Williams F. M. An approach to the nonlinear behavior of members of a rigid jointed plane framework with finite deflections. Quarter Applied Mathematics 17 (1964), 451-469.

14. Wood R. D. and Zienkiewicz O. C. Geometrically nonlinear finite element analysis of beams, frames, arches and axisymmetric shells. Computer \& Structures 7 (1977), 725-735. 
15. Hisao K. M. and Huo F. Y. Nonlinear finite element analysis of elastic frames. Computers \& Structures 26 (1987), 693-701.

16. Ciclon C. Large displacement in-plane analysis of elastic-plastic frames. Computers \& Structures 19 (1984), 737-745.

Received December 8, 2002

\section{PHÂN TÍCH KHUNG CÓ ĐÔ VÕNG LỚN \\ BẰNG PHẦN TỬ HŨU HẠN CHỨA CÁC THỪA SỐ BẬC CAO}

Bài báo trình bày công thức phần tử hữu hạn sử dụng các thừa số bậc cao cho phân tích khung đàn hồi có độ võng lớn. Các phần tự được xây dựng trên cơ sớ phương pháp hệ tọa độ đồng hành và biểu thức năng lượng biến dạng. Đường cân bằng kết cấu được tính theo phương pháp độ dài cung. Các ví dụ số chỉ ra rằng trong khi thừa số bậc hai của góc quay địa phương cải thiện phần nào độ chính xác, kết quả số hầu như không thay đổi với sự tham gia của biến dạng dọc trục bậc cao. Phân tích sử dụng phần tử chứa số hạng bậc cao có thể đạt được độ chính xác với lưới thô hơn.

e-mail: abs@netnam.org.vn

\section{CÂN BẰNG MÁY QUAY TRONG TRƯỜNG HợP PHI TUYẾN KHI QUA VÙNG CộNG HUỜNG \\ Nguyễn Cao Mệnh, Trần Duang Trí}

(Tiếp trang 242)

Bài báo này trình bày một phương pháp cân bằng động máy quay được mô tá như hệ phi tuyến khi qua vùng cộng hương. Sau khi thiết lập hệ dao động phi tuyến, các lời giải số (hệ tuyến tính, phi tuyến), các phân tích dao động được đề xuất. Dựa trên các kết quả phân tích, một quy trình cân bằng động qua vùng cộng hường bao gồm đo dao động, xử lý tín hiệu và xác định các tham số để tính toán độ lớn và vị trí khối lượng mất cân bằng

dã được trình bày. Các thí dụ về mô hình và tính toán đã được thực hiện để minh họa cho phương pháp. 